\title{
Denervation in wasted hand muscles in a case of primary cerebellar ectopia without syringomyelia
}

\author{
SM ALANI \\ From the National Hospital for Nervous Diseases, Queen Square, London UK
}

SUMMARY Wasting of hand muscles and electromyographic changes of denervation in a case of primary cerebellar ectopia without evidence of syringomyelia is described. It is suggested that the wasting is due to anterior horn cell damage secondary to grey matter venous obstruction at high cervical cord levels.

Hand muscle wasting has been described in patients having primary cerebellar ectopia with syringomyelia. ${ }^{1}$ It has also been described with EMG evidence of denervation in cases of high cervical cord compression. ${ }^{2-5}$ This communication reports denervation changes in wasted hand muscles in a case of primary cerebellar ectopia with no evidence of syringomelia.

\section{Case report}

A 19-year-old trainee bricklayer presented with a 5 month history of weakness and wasting in the muscles of the left hand. He also noticed tingling in the left fingers and left side of the chest when bending his neck. There were no symptoms referable to either cranial nerves or the other limbs.

On examination, abnormalities were limited to the left upper limb. Weakness (MRC grade 4 to $4+$ ) was found in the thenar, hypothenar, interosseous, wrist extensor and flexor, extensor digitorum communis and triceps muscles. Wasting was also noted in these muscles, particularly in the interossei. There were no objective sensory abnormalities in any of the limbs. Reflexes were preserved and symmetrical with flexor plantar responses. There was no evidence of Horner's syndrome, spinal deformities or bruits, short neck or skin lesions.

Plain radiographs of the cervical spine were normal. Metrizamide myelography demonstrated herniation of the cerebellar tonsils down to $\mathrm{C} 2$ level and atrophy of the mid and lower cervical cord (fig). There was no variation in cord size with changes in patient position. Computed tomography

\footnotetext{
Address for reprint requests: Dr SM Alani, Dept of Clinical Neurophysiology, St James's University Hospital, Beckett St, Leeds LS9 7TF, UK.
}

Revised 19 January 1984 and in revised form 10 May 1984. Accepted 1 June 1984 with metrizamide confirmed the cord atrophy and showed no visible contrast within the cord substance on delayed scans (up to 24 hours). The cerebral ventricles were of normal size.

EMG, using a concentric needle electrode, demonstrated fibrillation, fasciculation and large polyphasic motor units of long duration in the left thenar, first dorsal interosseus, wriso flexor and extensor, extensor digitorum communis, bicep and triceps muscles. Similar but less severe changes were alse seen in the right biceps and first dorsal interosseous muscles. Median and ulnar motor conduction velocity, $F$ wave latency, finger to wrist sensory action potentials and somat sensory evoked potentials to median nerve stimulation we E normal in both upper limbs.

At operation, the posterior margin of the foramen magnum was removed and laminectomy of $\mathrm{Cl}$ and $\mathrm{C} 2$ was performed. Marked cerebellar ectopia was found, more pronounced on the left where the cerebellar tonsil extended down to C2 level. The cord, down to C3 level, appeared atrophic with no cystic enlargement. It was of normal consistency and was not collapsible or pulsatile. Needling of the cord was therefore judged to be unnecessary. The vertebral and anterior spinal arteries were not examined during surgery. Eighteen months after the operation, the patient reported no clinical deterioration and was back at full employment; preoperative EMG abnormalities were still evident.

\section{Discussion}

The hand muscle wasting presented in this case differs from that described previously in cases of primary cerebellar ectopia by the absence of dissociated anaesthesia or loss of reflexes in the upper limbs characteristic of syringomyelia. ${ }^{1}$ In a series of 100 cases of syringomyelia, ${ }^{6}$ none presented with muscular wasting alone; all cases of wasting were associated with loss of upper limb sensitivity and reflexes. 


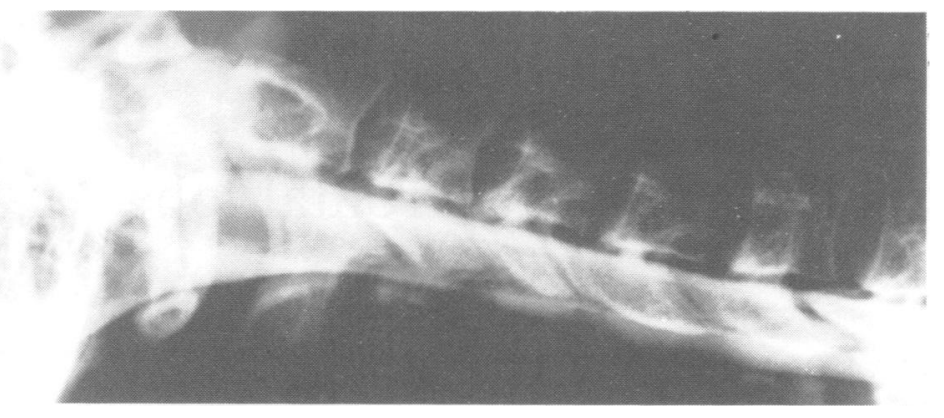

Fig Myelogram (metrizamide $300 \mathrm{mg} / \mathrm{ml}, 10 \mathrm{ml}, \mathrm{Cl}-2$ puncture). Supine position. The cerebellar tonsils are shown to descend to the level of $C 2$. The sagittal diameter of the cervical cord is reduced at $C 5$ and $C 6$ in the absence of any narrowing of the theca or spinal canal at these levels, suggesting atrophy.

Although the radiological and operative findings described have not demonstrated any evidence of an expanded cavity, they do not exclude a small central cleft in the cord. However, it is difficult to imagine such a lesion causing this extensive and severe wasting and bilateral denervation without interrupting central fibres and producing some loss in upper limb sensibility and reflexes. Indeed a case of cerebellar ectopia which came to necropsy and was shown to have a central cleft had presented with hand numbness rather than muscle wasting.?

From the evidence discussed above, it is concluded that syringomyelia is a most unlikely cause for the muscle wasting in this case. High cervical cord compression has long been associated with hand muscle wasting which was attributed to anterior horn cell damage. $^{2-4}$ In the case presented here, the clear denervation changes demonstrated in the absence of any radiological evidence of a root lesion and the normal sensory and $F$ wave studies suggest a similar pathology. The findings suggest that these are due to remote effects of cervical cord compression by the prolapsed cerebellar tonsils.

The mechanism leading to anterior horn cell damage is controversial. Ischaemia due to occlusion of the anterior spinal artery by the compressing mass is unlikely because of the asymmetry of clinical signs and the symmetry of anterior spinal artery distribution. ${ }^{8}$ Stagnation ischaemia secondary to obstruction of cervical cord venous drainage has also been suggested. ${ }^{3}$ This is supported by experimental high cord compression in monkeys which can produce hand muscle weakness. ${ }^{9}$ Venous dilatation, grey matter haemorrhages and anterior horn cell loss were found on both sides of the cervical cord but maximal at $\mathrm{C7}$, C8 level ipsilateral to the compression. The asymmetrical distribution of these pathological changes, which is similar to that of the clinical signs, and their restriction to the grey matter. have been attributed to separate venous drainage systems for white and grey matter which are independent on the two sides. However, EMG studies were not performed on the weak muscles to link the pathological and clinical findings.
From the available evidence and the cranial direction of cervical cord venous flow, ${ }^{10}$ this study suggests that the muscle wasting presented is due to anterior horn cell damage secondary to obstruction of the venous drainage of grey matter at the level of the cerebellar tonsillar herniation.

I am grateful to Dr JN Blau for permission to report this case and to Professor PK Thomas and Dr NMF Murray for helpful criticism of the manuscript.

\section{References}

${ }^{1}$ Mohr PD, Strang FA, Sambrook MA, Boddie HG. The clinical and surgical features in $\mathbf{4 0}$ patients with primary cerebellar ectopia (adult Chiari malformation). $Q J$ Med 1977;46:85-96.

${ }^{2}$ Symonds CP, Meadows SP. Compression of the spinal cord in the region of the foramen magnum. With a note on the surgical approach by Julian Taylor. Brain 1937;60:52-84.

${ }^{3}$ Stark RJ, Kennard C, Swash M. Hand Wasting in Spondylotic High Cord Compression: An Electromyographic Study. Ann Neurol 1981;9:58-62.

${ }^{4}$ Levison JA, Ransohoff J, Goodgold J. Electromyographic studies in a case of foramen magnum meningioma. $J$ Neurol Neurosurg Psychiatry 1973;36:561-4.

${ }^{5}$ Yasuoka S, Okazaki H, Daube JB, MacCarty CS. Foramen magnum tumours: analysis of 57 cases of benign extramedullary tumours. J Neurosurg 1978;49:828-38.

${ }^{6}$ Foster JB, Hudgson P. The clinical features of communicating syringomyelia. In: Barnett HJM, Foster JB, Hudgson P, eds. Syringomyelia. London: WB Saunders, 1973:16-29.

${ }^{7}$ Foster JB, Hudgson $P$. The pathology of communicating syringomyelia. In: Barnett HJM, Foster JB, Hudgson P, eds. Syringomyelia. London: WB Saunders, 1973: 79-103.

${ }^{8}$ Alexander GL. Foramen magnum and high cervical syndromes. Scot Med J 1958;3:329-340.

9 Taylor AR, Byrnes DP. Foramen magnum and high cervical cord compression. Brain 1974;97:473-80.

${ }^{10}$ Brain WR. Discussion on rupture of the intervertebral disc in the cervical region. Proc $R$ Soc Med 1948;41:509-11. 